\section{Of ticks and mites}

\section{Jim Berreen}

Experimental and Applied Acarology. Editor-in-chief W. Helle. Elsevier. 4/yr. Dfl. 204.

ACARology has for some time been the poor sister of entomology, both in relation to its range of published material and in the availability of journals from which to gain an overview of the subject. Elsevier's decision to launch Experimental and Applied Acarology was thus a positive move to enable the cross-fertilization of the various experimental approaches that previously were documented only in the proceedings of international conferences.

The editorial intention is to address a broad church, from field studies and behaviour through to toxicology and physiological systems. The restrictions are that manuscripts dealing with taxonomy and morphology will only be considered in experimental and control contexts, and faunistic studies need to be supported by an experimental approach. The initial volume reflected this choice well, with nine papers on the effects of pesticides, seven on field studies and 14 on laboratory investigations. Not surprisingly, there have been more papers on ticks than on any other group, but plant parasites and their predators came a close second.

The editorial board is widely international, and eminent, and this should attract an increasingly diverse and interesting range of papers. Certainly the contributions so far have been generally good to very good in quality, with a few delightful surprises like Knop's description of real behaviour and sperm transfer in a tydeid mite and Cunnington's definitive statement on oviposition and fecundity in the flour mite.

Overall, the presentation is of Elsevier's usual high quality. The reproduction standard of micrographs appeared to be adequate to my non-specialist eye, and I could identify all that the authors intended. Perhaps that is sufficient, even if the tonal range and definition of some of the plates may be rather less acceptable to the authors and more discerning critics.

The practice of printing figures drawn by graph plotters is an obvious mark of efficient progress in publishing. However, the fonts for plotters seem to have been designed by graphic gnomes with little concern for the reader - the difference in legibility between poor plotter and good printed output is so substantial that it demands an editorial reaction. One other, small idiosyncracy of the production is that narrow figures appear left justified. For graphs this gives the probably valuable impression that they have just hit the page, no doubt hot off the bench. How- ever for one figure, detailing the sampled sections of an ethnic cow (head (1), ears (2) ... tail (7) !), it gave the impression that the subject was just hobbling back to the bush on the two legs it had left - (4) and (6).

In addition to research papers and book reviews, the journal has also published a short review paper. This is especially encouraging, as review articles in acarology are all too rare and are valuable in stimulating new directions and ideas.

Both editor and publisher are to be congratulated on providing a forum which will undoubtedly increase the value and scope of research carried out on this still neglected yet economically important group of animals. The journal reflects the coming-of-age of acarology, and I hope that the editorial board will maintain their broad zoological perspective.

Jim Berreen is a Lecturer in the Department of Zoology and Comparative Physiology, University of Birmingham, Birmingham B15 2TT, UK.

\section{Life in the tropics}

\section{Gordon H. Orians}

Journal of Tropical Ecology. Editor Adrian G. Marshall. Cambridge University Press. 4/yr. UK £49 (institutional), $£ 19.50$ (individual); elsewhere $\$ 99$ (institutional), $\$ 39$ (individual).

THE present, a time of spreading desertification at low latitudes and of rapid conversion of tropical forests to other uses, is also experiencing an upsurge in interest in tropical ecosystems. Because tropical organisms, communities and ecosystems are so much more poorly known than temperate ones, there remains a need for basically descriptive ecological studies to accompany those with a more hypotheticodeductive approach. The high volume of manuscripts submitted to existing ecological journals makes it difficult for tropical researchers to publish primarily descriptive papers. Moreover, papers on tropical ecology are scattered among those reporting work done at higher latitudes.

To encourage the execution and publication of important descriptive research in tropical ecology, and to make the results of tropical research more accessible to ecologists living in tropical countries, The International Association for Ecology recommended initiating a new journal. Launched in 1985 as the Journal of Tropical Ecology, it accepts papers dealing with all aspects of tropical ecology, both "pure" and "applied", and includes both original research and reviews of literature. It is edited at the Institute of Southeast Asian Biology at the University of Aber-

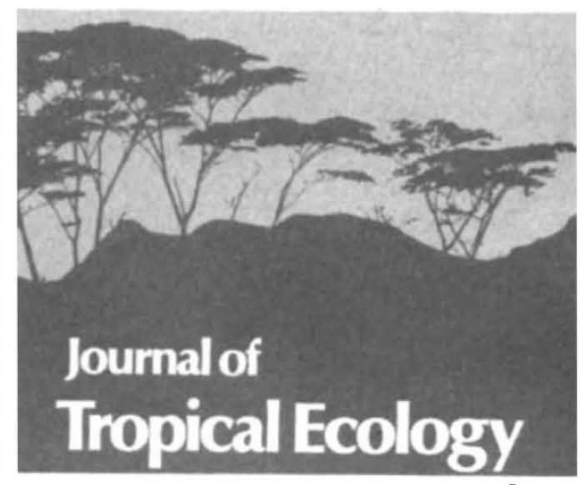

deen, Scotland, with the assistance of an editorial board drawn from leading tropical ecologists on all continents. Long and short articles, notes, notices, announcements of meetings, book reviews and editorial comments are all welcomed.

The first volume has a good balance among papers dealing with different taxa, and contains reports of research at all levels of ecological organization, from studies of single populations to ecosystem functioning, and from all areas of the tropics in both the New and Old Worlds. Already in its first year, the journal has received and published papers by leading researchers in tropical ecology. The papers actually are not noticeably more descriptive than those found in the mainline temperate zone ecology journals; indeed, the journal is already well on the way to becoming a major forum for interchange of ideas about tropical ecology, and all researchers working in the tropics or who attempt to follow the tropical literature will find it essential reading.

The decision was made, largely as a result of urging by people from non-English speaking nations, to accept papers only in English, but the editors have expressed a willingness to put in extra efforts to assist authors for whom English is not a native language. Contributions in the first volume are well-written, and despite the admission of the editor of having distinctive views of what constitutes good English, the unique styles of some of the contributors known to me have survived his editorial pen relatively unscathed.

The journal is attractively printed in single-column format and the quality of illustrations and tables is excellent. There were considerable delays in publishing parts of Vol. 1, the last issue not appearing until mid-1986, and it remains to be seen whether these were the result of the birth pains of a new endeavour or symptomatic of difficulties that may persist into childhood. It is, however, unlikely that the journal will suffer from a shortage of highquality manuscripts, and I suspect that pressure to expand from the current 100 page issue will soon face the editors.

Gordon H. Orians is Professor of Zoology and Director of the Institute for Environmental Studies at the University of Washington, Seattle, Washington 98195, USA. 